\title{
Research Article \\ Repeated heating of edible oils: effects on polyphenolic content and antioxidant capacity
}

Weerakoon $\mathrm{NP}^{1}$, Senadheera $\mathrm{S}^{1}$, Jayawardhana $\mathrm{I}^{1}$

${ }^{1}$ Rajarata University of Sri Lanka, Mihintale, Sri Lanka

\begin{abstract}
Dietary free radicals carry significant health risks. Antioxidant capacity and total phenolic content of seven edible oil types [coconut oil-I (loosely packed-wholesale), coconut oil-II (pure, sold in bottles), olive oil, soya oil, sunflower oil, palm oil and mee (Madhuca longifolia) oil] were measured at unheated, heated and reheated stages, to determine the effects of repeated heating on the antioxidant activity. Free radical scavenging assay - 2,2azinobis-3-ethylbenzothiazoline-6-sulphonate, expressed as Trolox equivalent antioxidant capacity (TEAC) per gram of oil and Folin-Ciocalteu method were used to determine the antioxidant capacity and the total polyphenolic content respectively. Statistical significance was tested using ANOVA Tukey's post-hoc test. At an unheated stage, mee oil had the highest antioxidant capacity $(220.71 \pm 5.45 \mu \mathrm{g} / \mathrm{g}$ TEAC) followed by olive oil $(22.10 \pm 2.77 \mu \mathrm{g} / \mathrm{g}$ TEAC) and coconut oil-I $(13.02 \pm 2.77 \mu \mathrm{g} / \mathrm{g}$ TEAC). Other unheated oils showed negligible antioxidant capacities. First heating significantly reduced $(p<0.05)$ the antioxidant capacity in all types of oils in which mee oil $(124.43 \pm 4.81 \mu \mathrm{g} / \mathrm{g}$ TEAC) showed the least reduction. This was followed by coconut oil-I $(7.57 \pm 2.10 \mathrm{TEAC} \mu \mathrm{g} / \mathrm{g})$. After the second heating, all the oils except mee-oil $(86.89 \pm 2.77 \mu \mathrm{g} / \mathrm{g}$ TEAC) showed negligible antioxidant capacities. Olive oil showed the highest percentage reduction (290\%) in antioxidant capacity from un-heated to the re-heated stage. At all the tested stages, mee-oil had the highest phenolic content $(12610.6 \pm 28.8,8471.70 \pm 68.0$ and 7345.91 \pm 78.6 Gallic Acid Equivalent/100 $\mathrm{g}$ of oil respectively). All the oil types showed a significant change in phenolic content from unheated to re-heated stage $(p<0.05)$. It can be concluded that heating and reheating of tested oil types cause significant reduction in antioxidant capacity. Of them, mee oil and coconut oil-I were comparatively safe to be re-used in cooking in terms of antioxidant capacity.
\end{abstract}

Keywords: Antioxidant capacity, Total phenolic content, Unheated oil, Heated oil, Reheated oil

Copyright: (C2019 Weerakoon NP et al. (c) (i)

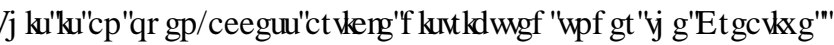

\&RP P RQVAttribution License, which permits unrestricted use, distribution, and reproduction in any medium, provided UKHRUJ IQDOwork is properly cited.

Funding: None

Competing interests: None

$\triangle$ Correspondence: isurijayawardana@yahoo.com

Cite this article as: Weerakoon NP et al. Repeated heating of edible oils: effects on polyphenolic content and antioxidant capacity. Anuradhapura Medical Journal 2019;13(1):4-11

DOI: http://doi.org/10.4038/amj.v13i1.7655

\section{Background}

As an energy source, a biomolecule of the plasma membrane and a precursor of several hormones, dietary oils play an important role in the human diet (1). In the human diet, oils are used in frying, baking, marinating and to increase the crunchiness of the food items. Flavour, colour and crispy texture given by oils improve the organoleptic qualities and the palatability of food (2).

Due to the cost-effectiveness, repeated use of cooking oils is frequent in both domestic and industrial food processing. However, long-term consumption of repeatedly heated vegetable oils could be detrimental (3) as free radicals and phenolic compounds formed during the process 
play a main role in the initiation, progression and aggravation of non-communicable diseases (4). During the frying process, cooking oil is exposed to an extremely high temperature in the presence of air and moisture. Such conditions activate a series of complex chemical reactions to alter the fatty acid composition by oxidation, hydrolysis, polymerization and isomerization, eventually resulting in lipid peroxidation and polyphenolic compound generation (5). Triacylglyceride oxidation and generation of unstable intermediates named hydroperoxides occur at high temperatures. These intermediates are rapidly broken down into reactive free radicals. All these chemical changes reduce the quality, texture and nutritional value of cooking oils $(6,7)$. Therefore, quantitative data are required to assess the effects of heating and repeated heating of different edible oils on humanhealth.

The chemical nature of the oil is one of the main determinants of the amount of free radical formation during heating. Edible oils possess different fatty acid compositions and thus generate different amounts of free radicals during heating (1). Antioxidants are important in neutralizing these free radicals and/or their actions (8). Some oils naturally contain high amounts of antioxidants (i.e., mostly polyphenolic compounds) and thus, scavenge the free radicals formed during the frying process. Therefore, natural antioxidants in oils can affect the ultimate quality and nutritional value of oils. However, antioxidants are highly heat-labile: hence, destruction of antioxidants during heating is unavoidable (6). The resistance and stability of antioxidants in different cooking oils to thermal oxidation are highly variable (9). Therefore, the amount of antioxidants at the unheated state is a crucial factor that determines the ultimate quality of fried oils or fried foods. The antioxidant capacity and the total polyphenol content of edible oils at unheated, heated and reheated stages would provide a guide to select better oils for reuse.

Being the main cooking oil, coconut oil is used for most types of culinary practices in Sri Lanka. Moreover, with the decrease in coconut cultivation and emerging myths related to coconut oil, a deviation from coconut oil consumption to other types of oils (e.g., sunflower oil, canola oil, virgin coconut oil, soybean oil, olive oil and palm oil, etc.) has been observed (10). In parallel, a significant reduction in using some of the traditional edible oils has been observed. Mee (Madhuca longifolia) oil which is an extract of mee seeds, is one such example. Currently, this oil is produced in limited quantities and its health benefits are hardly assessed.

This study aims to determine the antioxidant capacity and phenolic/polyphenolic content in different edible oils available in Sri Lanka and the effect of repeated heating on the antioxidant capacity of these oils.

\section{Methodology}

All the experiments were carried out at the research laboratory, Department of Biochemistry, Faculty of Medicine and Allied Sciences, Rajarata University of Sri Lanka, Saliyapura, Sri Lanka.

\section{Collection of oil samples}

Coconut (Cocos nucifera) oil-I (wholesale), coconut oil-II (pure, sold in bottles), soya (Glycine max) oil, sunflower (Helianthus annuus) oil, palm (Elaeis guineensis) oil, olive (Olea europaea) oil and mee oil samples were purchased from sales outlets in Anuradhapura. In addition to these, four oil samples that had been used in frying foods repeatedly (wade, murukku, and other shorteats,etc.) were collected from street shops in Anuradhapura town..

\section{Sample preparation}

From each of the oil bottles, which were directly bought from the shops, $100 \mathrm{ml}$ of oil was separated as unheated samples. Another $100 \mathrm{ml}$ from each of the above oils was heated by keeping samples at boiling phase for 5 minutes to obtain heated samples. Repeatedly-heated samples were prepared by boiling $100 \mathrm{ml}$ of each of the oil samples for another 5 minutes after the initial boiling. In between two heating steps, the samples were cooled for 10 minutes.

\section{Extraction of antioxidants from oil samples}

To extract the phenolic compounds, 5.0g from each of the unheated, heated and reheated oil samples were mixed with $1 \mathrm{ml}$ of methanol and water in $80: 20 \mathrm{v} / \mathrm{v}$. The samples were vortexed twice at $40 \mathrm{~Hz}$ for 2 minutes and then centrifuged at 1080xg for 10 minutes. The resultant clear solution was 
collected to a new tube. The same procedure was repeated four times with each of the oil samples. The resultant extracts were collected, diluted up to $5.0 \mathrm{ml}$ and stored in a dark place at $20^{\circ} \mathrm{C}$ in glass bottles covered with aluminium foil until further analysis.

\section{Determination of total phenolic contents by Folin-Ciocalteu method}

From each of the extracts, $1 \mathrm{~mL}$ was added into $2 \mathrm{~mL}$ of $10 \%$ (v/v) Folin-Ciocalteuand $10 \mathrm{~mL}$ of distilled water. After incubating the mixture at room temperature for 5 minutes, $2 \mathrm{ml}$ of $0.7 \mathrm{M} \mathrm{Na}_{2} \mathrm{CO}_{3}$ was added, mixed well and kept for 30 minutes at room temperature. Light absorbance at $725 \mathrm{~nm}$ was measured using a visible spectrophotometer (LabomedSpectro 2000RS, U.S.A) against a reagent blank [Folin-Ciocalteu reagent $(2 \mathrm{~mL})$, distilled water (10ml), $\left.0.7 \mathrm{M} \mathrm{Na} \mathrm{Na}_{2} \mathrm{CO}_{3}(2 \mathrm{ml})\right]$ (11). Total phenolic content was calculated using astandard graph plotted using gallic acid as the standard.

\section{Standard curve for gallic acid}

A stock solution was prepared by dissolving $0.1 \mathrm{~g}$ of Gallic acid in $100 \mathrm{ml}$ of distilled water in a volumetric flask. From the stock solution, a dilution series consisted of 30,60, 90, 120, 150, and $180 \mu \mathrm{g} / \mathrm{ml}$ was prepared. From these samples, $1 \mathrm{ml}$ was taken and the same procedure to extract polyphenolic compounds was performed as for the test samples. The absorbance was measured at 725 $\mathrm{nm}$ and a standard curve was plotted for absorbance against the concentration of gallic acid.

\section{Determination of antioxidant capacity}

Two methods, namely 2, 2-azinobis-(3ethylbenzothiazoline-6-sulphonate) (ABTS) free radical scavenging assay (12) and 2, 2-diphenyl-1picrylhydrazyl (DPPH) free radical scavenging assay at $734 \mathrm{~nm}$ were used to determine the antioxidant capacity.

\section{Standard curve for ABTS radical (ABTS ${ }^{+}$) activity on Trolox}

A stock solution of 6-hydroxy-2, 5, 7, 8tetramethylchroman-2-carboxylic acid (Trolox) was prepared by dissolving $0.0161 \mathrm{~g}$ of trolox in $50 \mathrm{ml}$ of deionized water. From the prepared stock solution, $5 \mu 1,15 \mu 1,20 \mu 1$ and $25 \mu l$ volumes were mixed with $\mathrm{ABTS}^{+}$solution with an initial absorbance of $0.700 \pm 0.020$ at $734 \mathrm{~nm}$. The final volume was adjusted to $3 \mathrm{ml}$ using phosphate saline buffer. Light absorbance at $734 \mathrm{~nm}$ was recorded every 30 seconds for 6 minutes and the reduction of light absorbance from 0 to 6 minutes was calculated. Six duplicates were carried out for each concentration. A standard curve was plotted with the mean reduction of absorbance versus the quantity of trolox in $\mu \mathrm{g}$.

\section{Measurement of ABTS free radical cation} scavenging capacity in different samples

From each prepared unheated, heated and reheated oil sample extracts, $15 \mu \mathrm{Lwas}$ added and mixed well with $2.9 \mathrm{~m}$ of $\mathrm{ABTS}^{+}$solution (initial absorbance of $0.700 \pm 0.020$ at $734 \mathrm{~nm}$ ) in $85 \mu \mathrm{L}$ of phosphate saline buffer (total volume of $3 \mathrm{ml}$ ). Light absorbance was measured at every 30 seconds for over 6 minutes and the reduction of the absorbance at every 30 seconds was calculated (12). Antioxidant capacity was expressed as $(\mu \mathrm{mol} / \mathrm{g})$ trolox equivalent antioxidant capacity (TEAC). Trolox was used as the standard.

\section{Determination of 2, 2-diphenyl-1-picrylhydrazyl (DPPH) radical scavenging capacity}

DPPH radical scavenging ability of oil extracts was evaluated according to the method described by Lee et al., 2007 (13).

\section{Preparation of DPPH stock solution}

DPPH stock solution was prepared by dissolving 4 $\mathrm{mg}$ of DPPH in $100 \mathrm{ml}$ of $95 \%$ methanol.

DPPHfree radical scavenging capacity of unheated, heated and reheated oil samples

Concentration series (100, 200, 500, 1000, 1500 $\mu \mathrm{g} / \mathrm{ml}$ ) from methanolic oil extracts (unheated, heated and reheated oil) was prepared for all oil samples separately. For each methanol extract sample $(1 \mathrm{ml})$, DPPH $(1 \mathrm{ml})$ was added, maintaining a total volume of $2 \mathrm{ml}$. The mixture was shaken well and incubated for 15 minutes in dark at room temperature. Light absorbance was read at $517 \mathrm{~nm}$ using avisible spectrophotometer against $2 \mathrm{ml}$ of DPPH stock solution (blank). The percentage of free radical scavenging capacity was calculated using the formula below. 


$$
\begin{aligned}
& \text { Scavenging capacity(\%) } \\
& =\frac{(\text { Absorbance of blank solution }- \text { Absorbance of sample })}{(\text { Absorbance }} \times 100
\end{aligned}
$$

The scavenging capacity (\%) was plotted against the concentration of the sample and the $\mathrm{IC}_{50}$ value (concentration for $50 \%$ scavenging capacity) was obtained.

\section{Data analysis}

Statistical significance among the samples at 95\% confident interval was analysed by ANOVA Tukey's posthoc test using Statistical Analysis Software package (SAS)

\section{Results}

Total phenolic content in unheated, heated and reheated oil samples

The total phenolic content of seven oil samples in unheated, heated and reheated stages are shown in Table 1. Mee oil elicited the highest total phenolic content at all three stages, although a decreased concentration was observed with heating. An increase in the total phenolic content in coconut oil I, sunflower oil and coconut oil II was observed with heating. However, reheating caused a reduction of phenolic content in these oils.

Table 1: Total phenolic contents in unheated, heated and reheated oil

\begin{tabular}{|c|c|c|c|}
\hline Oil type & $\begin{array}{c}\text { Unheated oil } \\
\text { 1Total phenolics } \\
\text { (mg GAE/100g ) }\end{array}$ & $\begin{array}{c}\text { Heated oil } \\
\text { 1Total phenolics } \\
\text { (mg GAE/100g ) }\end{array}$ & 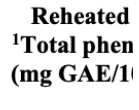 \\
\hline $\begin{array}{l}\text { Coconut oil } \\
\text { (whole sale) }\end{array}$ & $2.28 \pm 0^{c}$ & $2.62 \pm 18.9^{b}$ & $2.24 \pm 18 . !$ \\
\hline Olive oil & $3.36 \pm 49.9^{\mathrm{b}}$ & $2.64 \pm 37.7^{\mathrm{b}}$ & $2.28 \pm 18$. \\
\hline Sunflower oil & $0.61 \pm 28.8^{\mathrm{g}}$ & $1.11 \pm 32.7^{\mathrm{e}}$ & $1.12 \pm 28$ \\
\hline Pure coconut oil & $0.91 \pm 47.5^{\mathrm{f}}$ & $2.01 \pm 43.6^{c}$ & $1.10 \pm 28$ \\
\hline Soya oil & $2.10 \pm 21.8^{\mathrm{d}}$ & $1.63 \pm 60.7^{\mathrm{d}}$ & $2.12 \pm 76$ \\
\hline Mee oil & $12.61 \pm 28.8^{\mathrm{a}}$ & $8.47 \pm 68.0^{\mathrm{a}}$ & $7.34 \pm 78.1$ \\
\hline Palm oil & $1.87 \pm 49.9^{\mathrm{e}}$ & $1.67 \pm 28.8^{\mathrm{d}}$ & $1.46 \pm 29 .$. \\
\hline
\end{tabular}
samples

${ }^{1} \mathrm{n}=3$; GAE-Gallic acid equivalent; FW- fresh weight (Grouping from Tukey' that do not share a letter are significantly different at $5 \%$ probability level)
Total phenolic contents in oil samples obtained from sales outlets

The total phenolic contents of four oil samples obtained from sales outlets are shown in Table 2. A significant difference $(\mathrm{p}<0.05)$ was observed between the oil samples obtained from sales outlets in which the highest total phenolic content was observed from the oil sample obtained from the sales outlet 01 .

Table 2: Total phenolic contents in oil samples obtained from sales outlets (Method 02)

\begin{tabular}{ll}
\hline Oil type & $(\boldsymbol{m g ~ G A E} / 100 \mathrm{~g})$ \\
\hline Sales outlet 01 & $2.79 \pm 37.7^{\mathrm{a}}$ \\
Sales outlet 02 & $1.89 \pm 47.5^{\mathrm{b}}$ \\
Sales outlet 03 & $1.58 \pm 39.3^{\mathrm{c}}$ \\
Sales outlet 04 & $1.55 \pm 28.8^{\mathrm{c}}$ \\
\hline
\end{tabular}

${ }^{1} \mathrm{n}=3$; GAE-Gallic acid equivalent; FW- fresh weight (Grouping from Tukey's test, means that do not share a letter are significantly different at $5 \%$ probability level)

Antioxidant capacity of unheated, heated and reheated oil samples

The antioxidant capacities of seven types of oils in unheated, heated and reheated stages are shown in Table 3. In all three stages, mee oil showed the highest antioxidant capacity, although a reduction was observed with heating. The second and third highest antioxidant capacities were elicited by coconut oil and olive oil, respectively, while other oils showed negligible values. Except for sunflower and soya oils which elicited a slight increase, all other oils elicited decreasing antioxidant capacities when heating and reheating. However, sunflower oil, pure coconut oil, soya oil and palm oils elicited negligible values in all three stages.

Among other oils, mee oil elicited the lowest percentage reduction $(61 \%)$ of antioxidant capacity with heating.

Although olive oil had a high antioxidant capacity at unheated stage, a drastic percentage decrease in antioxidant capacity (290\%) was observed with heating. 
Table 3 Trolox equivalent antioxidant capacity of unheated, heated and reheated oil samples

\begin{tabular}{|c|c|c|c|c|c|c|c|}
\hline \multirow[t]{2}{*}{ Oil type } & \multicolumn{2}{|l|}{ Unheated oil } & \multicolumn{2}{|l|}{ Heated Oil } & \multicolumn{2}{|l|}{ Reheated oil } & \multirow{2}{*}{$\begin{array}{l}\text { Antioxidant } \\
\text { reduction } \\
\% \\
\%\end{array}$} \\
\hline & $\begin{array}{l}\text { TEAC } \\
(\mu \mathrm{g} / \mathrm{g})\end{array}$ & $\%$ & $\begin{array}{l}\text { TEAC } \\
(\mu \mathrm{g} / \mathrm{g})\end{array}$ & $\%$ & $\begin{array}{l}\text { TEAC } \\
(\mu \mathrm{g} / \mathrm{g})\end{array}$ & $\%$ & \\
\hline $\begin{array}{l}\text { Coconut oil } \\
\text { (whole sale) }\end{array}$ & $13.02 \pm 2.77^{\mathfrak{c}}$ & 6.72 & $7.57 \pm 2.10^{\mathrm{b}}$ & 5.9 & $\begin{array}{l}\text { Negligible } \\
\left(-6.36 \pm 0^{b}\right)\end{array}$ & 5.17 & 149 \\
\hline Olive oil & $22.10 \pm 2.77^{\mathrm{b}}$ & 7.58 & $\begin{array}{l}\text { Negligible } \\
\left(-14.23 \pm 2.77^{c}\right)\end{array}$ & 4.64 & $\begin{array}{l}\text { Negligible } \\
\left(-42.08 \pm 4.57^{\mathrm{cd}}\right)\end{array}$ & 2.52 & 290.41 \\
\hline Sunflower oil & $\begin{array}{l}\text { Negligible } \\
\left(-36.63 \pm 1.05^{\text {de }}\right)\end{array}$ & 2.90 & $\begin{array}{l}\text { Negligible } \\
\left(-23.31 \pm 3.78^{\mathrm{d}}\right)\end{array}$ & 4.12 & $\begin{array}{l}\text { Negligible } \\
\left(-41.48 \pm 2.77^{c}\right)\end{array}$ & 2.60 & -13.24 \\
\hline Pure coconut oil & $\begin{array}{l}\text { Negligible } \\
\left(-42.08 \pm 5.24^{\mathrm{e}}\right)\end{array}$ & 2.53 & $\begin{array}{l}\text { Negligible } \\
\left(-46.93 \pm 5.24^{\mathrm{f}}\right)\end{array}$ & 2.16 & $\begin{array}{l}\text { Negligible } \\
\left(-46.93 \pm 2.77^{\mathrm{d}}\right)\end{array}$ & 2.17 & -11.53 \\
\hline Soya oil & $\begin{array}{l}\text { Negligible } \\
\left(-35.42 \pm 1.82^{\mathrm{de}}\right)\end{array}$ & 3.08 & $\begin{array}{l}\text { Negligible } \\
\left(-33.61 \pm 1.82^{\mathrm{e}}\right)\end{array}$ & 3.20 & $\begin{array}{l}\text { Negligible } \\
\left(-38.45 \pm 2.77^{\mathfrak{c}}\right)\end{array}$ & 2.82 & -8.55 \\
\hline \multirow[t]{2}{*}{$\begin{array}{l}\text { Mee oil } \\
\text { Palm oil }\end{array}$} & $220.71 \pm 5.45^{\mathrm{a}}$ & 23.70 & $124.43 \pm 4.81^{\mathrm{a}}$ & 15.53 & $86.89 \pm 2.77^{\mathrm{a}}$ & 13.25 & 61 \\
\hline & $\begin{array}{l}\text { Negligible } \\
\left(-31.79 \pm 6.55^{d}\right)\end{array}$ & 3.33 & $\begin{array}{l}\text { Negligible } \\
\left(-45.72 \pm 6.38^{f}\right)\end{array}$ & 2.45 & $\begin{array}{l}\text { Negligible } \\
(-49.26 \pm 5.84\end{array}$ & 17.84 & - \\
\hline
\end{tabular}

${ }^{1} \mathrm{n}=3$; TEAC- ${ }^{1}$ Trolox Equivalent Antioxidant Capacity

(Grouping from Tukey's test, means that do not share a letter are significantly different at 5\% probability level)

Table 4 Trolox equivalent antioxidant capacity of oil samples obtained from sales outlets

\begin{tabular}{ccc}
\hline Oil types & ${ }^{1}$ TEAC $(\mu \mathrm{g} / \mathrm{g})$ & $\%$ \\
& & \\
\hline Sales outlet 01 & $-19.68 \pm 8.39^{\mathrm{a}}$ & 4.45 \\
Sales outlet 02 & $-49.35 \pm 4.20^{\mathrm{b}}$ & 1.95 \\
Sales outlet 03 & $-59.64 \pm 3.78^{\mathrm{bc}}$ & 1.12 \\
Sales outlet 04 & $-56.01 \pm 2.10^{\mathrm{e}}$ & 1.45 \\
\hline
\end{tabular}

${ }^{1} \mathrm{n}=3$; TEAC- 'Trolox Equivalent Antioxidant Capacity/ weight; (Grouping from Tukey' test, means that do not share a letter are significantly different at $5 \%$ probability level)

Trolox equivalent antioxidant capacity of oil samples obtained from sales outlets

The antioxidant capacity of four oil samples obtained from sales outlets is shown inTable 4, and the antioxidant capacities of all four samples were negligible.

\section{Discussion}

The polyphenolic content and the antioxidant capacity of seven edible oils were analysed in this study to identify the effect of heating and reheating on the quality of oil. Phenolic content of the unheated oils was significantly different $(p<0.05)$ from each other. This variation could be attributed to the differences in phenolic compounds and compositions in different varieties of oil seeds (14). In our study, mee oil showed the highest polyphenolic content and it was comparable to the already reported value $(13.6 \pm 0.05 \mathrm{mg}$ GAE/100g) by Bopitiya and Madhujith, 2012 (15). This oil is known to have several bioactive compounds, including phytosterols, sterol esters, triterpene alcohols, gamma-oryzanol, tocopherols, tocotrienols and other phenolic compounds (15). Although its phenolic content decreased with heating and reheating, mee oil showed the highest phenolic content at all three stages, indicating better stability of its phenolic compounds. According to the results of ABTS assay, mee oil possessed the highest antioxidant capacity at all unheated, heated and reheated stages. Our study showed a higher antioxidant capacity of unheated mee oil $(220.71 \mu \mathrm{g} / \mathrm{g})$ than the value $(31 \mu \mathrm{g} / \mathrm{g})$ reported by Bopitiya and Madhujith, 2012 (15). Type of extraction method (extracted into methanol by passing the oil through a glass column containing silica), environmental and climatic conditions of the area where the mee plant was 
grown (16) and the type of oil extraction method can be some of the contributing factors for this observed difference.

Phenolic content of some of the oils in this study was different from the already reported values. For example, according to the study conducted by Sreeramulu and Raghunath, 2011 in India, phenolic content in sunflower oil and palm oil were 1.5 \pm 0.2 GAE $/ 100 \mathrm{~g}$ and $3.2 \pm 0.2 \mathrm{GAE} / 100 \mathrm{~g}$, respectively (17). Observation of lower $(0.61 \pm 28.8 \mathrm{GAE} / 100 \mathrm{~g}$, $1.87 \pm 49.9 \mathrm{GAE} / 100 \mathrm{~g}$ ) values in our study could be due to the processing method of oils by different manufacturers, storage quality and the differences in the methods used to extract phenolic compounds (18). Moreover, in our study, soya oil and sunflower oil showed negligible antioxidant capacities, which are in contrast to a study done in Italy in which $2.20 \mathrm{mmol}$ Trolox $/ \mathrm{kg}$ and $1.17 \mathrm{mmol}$ Trolox/kg antioxidant capacities were reported for two oils, respectively (19). The extraction method used in this study is capable of extracting non-polar antioxidant compounds as well. Therefore, these two oil types can be assumed to be rich sources of non-polar antioxidant compounds rather than polar antioxidant compounds. Heating and reheating caused a reduction in phenolic content in many of the oils. In contrast, after heating coconut oil, sunflower oil and pure coconut oil elicited significantly high total phenolic contents $(p<0.05)$. Heat can cleave the existing polyphenolic and phenolic compounds leading to the formation of several new phenolic compounds (20). Therefore, the rise in polyphenolic content in those oil samples could be due to the formation of new polyphenolic compounds. Simple heating cannot cleave covalently bound phenolic compounds, yet, high temperatures can cleave these bonds making new phenolic compounds (13). However, the antioxidant capacity of these newly formed phenolic compounds is not yet clearly understood. Indicating the less functional capacity of newly formed phenolic compounds, our study showed an overall reduction in antioxidant capacity in heated and reheated oil samples compared to fresh samples. Moreover, negligible antioxidant capacities were observed for all the oil samples obtained from sales outlets even with considerable amounts of total phenolic contents. The formation of phenolic compounds with repeated heating, which does not possess antioxidant capacities, could be the reason for this outcome. Further, it is proven that there is a significantly high formation of free radicals and oxidants in oils with repeated heating (6).

Some of the newly formed phenolic compounds might also play the role of oxidants (20) and, therefore, the safeness of repeatedly heated oils could not be explained merely by the total phenolic content.

Storage conditions have a significant impact on antioxidant capacity. A previous study in Sri Lanka showed a higher phenolic content $(7.8 \pm 2 \mathrm{mg}$ GAE/100g, $6.2 \pm 2 \mathrm{mg} \mathrm{GAE} / 100 \mathrm{~g}$ ) in freshly extracted coconut oil using the cold extraction method (21). The values obtained in our study were lower than this reported value. As the tested samples in the current study were purchased from the market, this difference could be due to the effect of storage conditions.

Furthermore, higher phenolic concentrations in coconut kernel and higher temperatures during oil extraction favour the incorporation of more phenolic substances into coconut oil (21). The amount of phenolic compounds extracted into oil, also varies with the composition of coconut endosperm (21). Therefore, low total phenolic content in coconut oil in the present study also could be due to the low temperature used for the extraction of oil and due to differences in the coconut endosperm.

Reheating was associated with a significant reduction in total phenolic contents in all the oil types. This was previously shown by Daskalaki et al, 2009 in which the degradation of phenolic compounds during frying and the negative correlation between the total phenolic content and the frying time was identified (16).

\section{Conclusions}

High phenolic content and the antioxidant capacity with least reduction during heating and reheating were identified in mee oil; one of the traditional cooking oils in Sri Lanka. Therefore, of the tested oils, mee oil is the best oil that can be used for repeated cooking in terms of antioxidant capacity. Moreover, new phenolic compounds formed during heating have reduced antioxidant capacities. 


\section{References}

1. Vaskova H, Buckova M. Thermal degradation of vegetable oils: Spectroscopic measurement and analysis. Procedia Engineering. 2015;100:630-635.

2. Boskou G, Salta FN, Chiou A et al. Content of trans, trans-2, 4-decadienal in deep-fried and pan-fried potatoes. European Journal of Lipid Science and Technology. 2006;108(2):109-115.

3. Kamsiah J, Yusof K. Repeatedly heated vegetable oils and lipid peroxidation. INTECH, Chapter. 2012; 10:211-228.

4. Fullana A, Carbonell-Barrachina AA, Sidhu S. Comparison of volatile aldehydes present in the cooking fumes of extra virgin olive, olive, and canola oils. Journal of agricultural and food chemistry. 2004;52(16):5207-5214.

5. Choe E, Min DB. Chemistry of deepfat frying oils. Journal of food science. 2007;72(5):R77-86.

6. Leong XF, Ng CU, Jaarin $\mathrm{K}$ et al. Effects of repeated heating of cooking oils on antioxidant content and endothelial function. Austin Journal of Pharmacology and Therapeutics. 2015;3(2):1068.

7. Rani AKS, Reddy SY, Chetana R. Quality changes in trans and trans free fats/oils and products during frying. European food research and technology. 2010;230(6):803-811.

8. SiesH. Biochemistry of oxidative stress.AngewandteChemie InternationalEdition in English. 1986; 25(12):1058-1071.

9. Aydenız B, Yilmaz E. Performance of different natural antioxidant compounds in frying oil. Food technology and biotechnology. 2016;54(1):21-30.

10. Gunathilake HM, Samarajeewa S. Consumer demand for coconut oil. Coconut Research Institute. 2002; Available at: http://cri.nsf.ac.lk//handle/1/3992

11. Singleton VL, Orthofer R, Lamuela-Raventós RM. Analysis of total phenols and other oxidation substrates and antioxidants by means of folin-ciocalteure agent. Methods in enzymology. 1999; 299:152-178.

12. Re R, Pellegrini N, Proteggente A et al. Antioxidant activity applying an improved ABTS radical cationdecolorization assay.Free radical biology and medicine. 1999; 26(9):1231-1237.

13. Lee YL, Huang GW, Liang $\mathrm{ZC}$ et al. Antioxidant properties of three extracts from Pleurotuscitrinopileatus. LWT-Food Science and Technology. 2007;40(5):823-833.

14. Formo MW, Jugermann E, Norris FA et al. Physical properties of fats and fatty acids, 4th ed. In: Swern, D. (Ed.), Bailey's industrial oil and fat iproducts, Vol, John Wiley and Sons, New York. 1979; $177-232$.

15. Bopitiya D, Madhujith T. Antioxidant activity and total phenolic content of mee (Madhuca sp.)Oil, Book of Abstract of the Peradeniya University research Sessions, Sri Lanka.2012; 17.

16. Daskalaki D, Kefi G, Kotsiou K et al. Evaluation of phenolic compounds degradation in virgin olive oil during storage and heating. Journal Of Food \& Nutrition Research. 2009; 48(1).

17. Sreeramulu D, Raghunath M. Antioxidant and phenolic content of nuts, oil seeds, milk and milk products commonly consumed in India. Food and Nutrition Sciences. 2011; 2(05): 422.

18. Sing RP, Murthy KNC, Jayapra-kash GK. Studies on the antioxidant activity of pomegran-ate peel and seed extracts using in vitro models, Journal of Agricultural and Food Chemistry. 2002;50(1):81-86.

19. Pellegrini N, Serafini M, Colombi B et al. Total antioxidant capacity of plant foods, beverages and oils 
consumed in Italy assessed by three different in vitro assays. The Journal of nutrition. 2003;133(9):2812-2819.

20. Turkmen N, Sari F, Velioglu YS. The effect of cooking methods on total phenolics and antioxidant activity of selected green vegetables. Food Chemistry. 2005;93(4):713-718.

21. Seneviratne KN, Hapuarachchi CD, Ekanayake S. Comparison of the phenolic-dependent antioxidant properties of coconut oil extracted under cold and hot conditions. Food Chemistry. 2009;114(4):14441449. 